\title{
An Evaluation of the Teaching Approach for the Interdisciplinary Course Electrical Engineering for Non Majors
}

\author{
S. A. Zekavat ${ }^{1}$, C. Sandu ${ }^{2}$, G. Archer ${ }^{1}$, and K. Hungwe ${ }^{3}$ \\ ${ }^{1}$ Dept. of Electrical and Computer Engineering, Michigan Tech University, Houghton MI 49931, \\ ${ }^{2}$ Dept. of Mechanical Engineering, Virginia Polytechnic Institute and State University, Virginia, 24061, \\ ${ }^{3}$ Dept. of Education, Michigan Tech University, Houghton MI 49931.
}

\begin{abstract}
This paper presents an evaluation on the teaching approach for the interdisciplinary course "Introduction to Electrical Engineering (EE) for non-EE majors" performed by surveying three groups from the Michigan Tech Department of Mechanical Engineering-Engineering Mechanics (ME-EM): 1) undergraduate students who had already taken the traditional EE service course, 2) graduate students, some of whom had taken a similar undergraduate course, and some who had not, and 3) the faculty. The results of this preliminary study indicate that more than $75 \%$ of those surveyed believe that there are problems associated with the traditional curriculum and teaching strategies for this course. This depicts that this course should be optimized and new techniques should be developed for presentation of the course. We explain a novel technique for optimizing this interdisciplinary.
\end{abstract}

\section{Introduction}

There is a remarkable development that is having a profound impact on the full spectrum of engineering. This is the increasing penetration of advanced topics of electrical engineering (EE) into other - and often traditionally unrelated - engineering fields. As a result, the cross-correlation among different engineering disciplines is increasing [1]. Various branches of electrical and information engineering are acknowledged as core emerging technologies that are critical for the future of this nation's economic prosperity [2]. The interconnectivity of electrical engineering with other engineering disciplines demands that our universities train engineering professionals who are fully competent in all aspects of EE relevant to their work.

One key mission of university baccalaureate engineering programs is to develop and offer the interdisciplinary coursework that is essential to preparing highly-qualified engineering graduates who will be successful and productive in their future careers [3]. To this end, it is generally recognized in the academic environment that an introductory course in EE should be offered to the non-electrical engineering (non-EE) students. As a result, almost all engineering institutions offer at least one "service course" for non-EE majors through the EE department. It is the responsibility of the academic programs to ensure that these service courses remain relevant to the real world of engineering that their graduates will encounter.

Therefore, in this contemporary context, it is reasonable to ask the following questions: 
1. What concepts, covered to what level of detail, should be included in the education of students of various engineering disciplines to prepare non-EE engineers to efficiently solve the interdisciplinary problems in today's scientific and engineering environment?;

2. Is the current approach used in teaching this course in harmony with the goals of nationally recognized organizations which dedicate at least part of their mission to improve engineering education (such as the National Science Foundation (NSF) [4], the Accreditation Board for Engineering Technology (ABET) [5]-[8], the National Research Council's Board on Engineering Education [9], [10], and the American Society for Engineering Education [11], [12]) and the themes of "application of emerging technologies" and "education for manufacturing"? [9];

3. Will current teaching strategies be able to keep pace with emerging technologies and their related instructional requirements? [13];

4. How will industry's expectations for entry level engineers be satisfied through interdisciplinary education? [14];

5. Given that students' enthusiasm increases if they understand why they should learn a topic, how can they be motivated to engage and master concepts not directly related to their chosen field? [15], [16]; and,

6. Finally, how will these complementary (and sometimes conflicting) requirements be satisfied within the resource constraints of the modern engineering educational institution?

Traditionally, the content of the EE service course is a cut-and-paste combination of some of the content of courses offered to EE students. This practice is not consistent with growing interdisciplinary technology and it does not adequately fulfill students' future needs. The traditional approach covers some limited topics in EE in detail but does not cover the broad range of technologies in the field of electrical engineering.

Topics that are commonly taught in service courses with the same detail as in EE courses include, for example, "circuits with resistors, capacitors and inductors," "transient response," and "AC analysis." EE majors require an in-depth study of these topics as a prerequisite for future coursework, but this is not true for non-EE majors. There are at least two problems that result from this misplaced emphasis on EE topics. First, because non-EE students do not continue to use many of these concepts in their later classes or in their careers, they frequently forget the details of what they have learned. Second, the class time devoted to the details of circuit theory in a service course detracts from the time needed to study and understand the connections between electrical engineering and related engineering fields. As a result, non-EE students regularly express dissatisfaction with the traditional service course and increasingly maintain that the course should no longer be required in their programs of study. This students' feeling has been experienced by many members of faculty teaching this course in various universities.

A number of universities recognized the problem in the traditional EE service course tried to address them by requiring an additional course for non-majors offered by the EE department. Mississippi State University (MSU) offers a second service course EE 3283 "Electronics" [17]. The University of Maryland has split the course into a 2-semester, 6-credit course "Measurement I and II" [18]. One problem associated with the approach chosen by these universities is that the extra course is structured to meet the needs of only one area of engineering that of mechanical engineering. Another problem is that these universities have chosen to increase the number of 
required courses rather than to optimize the current course. Furthermore, this increase in credits accommodates just one engineering major and is not an option for other non-EE students.

A number of Michigan Tech faculty suspected that students were not satisfied with the current content of the EE service course. Faculty experience and routine course evaluations by students show that: (1) students are concerned with the current curriculum that covers many topics more extensively than needed, (2) there is no clear link between the subjects taught and the students' fields of study, (3) many topics do not apply to the students' fields, they are soon forgotten, and, (4) the course does not cover many topics the students believe are more relevant to their future careers. This experience formed the basis of a preliminary study conducted at Michigan Tech University.

This paper presents a preliminary study on the weakness of the current approach in teaching the interdisciplinary course "Introduction to Electrical Engineering (EE) for non-EE majors". The study was performed by surveying three groups from the Michigan Tech Department of Mechanical Engineering-Engineering Mechanics: (1) undergraduate students who had already taken the traditional EE service course, (2) graduate students, some of whom had taken a similar undergraduate course and some who had not, and (3) the faculty. More than 90 faculty, undergraduate students, and graduate students participated in our study. Surveys were designed for each group to measure the degree of their satisfaction with the current course content as well as their perceived need to learn more about topics in EE not covered by the current course. A typical survey designed for students is included in as Appendix 1 of this paper.

The results of this preliminary study confirm the experiences of the faculty and the feedback they have received in prior offerings of this course. More than $75 \%$ of those surveyed believe that more information on newer EE topics should be included in the course. Specifically, they believe learning more about current developments in different fields of EE such as "radar systems", "wireless systems", "antenna systems", and "robotics" will help their future career.

In this paper, we also present a novel approach for optimizing the EE service course for nonmajors. The optimized course should include relevant topics at an appropriate level of detail and should feature web-based material where feasible. Fundamental knowledge, as well as information regarding emerging technologies should be incorporated into the course.

In Section II we present current teaching approach at MTU. Section III presents the preliminary study and results conducted at MTU. Section IV details the proposed approach for optimizing the course, and Section IV concludes this paper.

\section{Current Teaching Approach at MTU}

In its current form, the course in electrical engineering for non-EE majors, EE3010, "Circuits and Instrumentation", follows the traditional lecture-laboratory format. It consists of two hours of lecture and two hours of laboratory per week. At MTU this course is required for mechanical engineering and biomedical engineering majors and forms the foundation for their instrumentation sequence. The civil engineering department is considering requiring EE 3010 as part of its core curriculum. Approximately 150 students per semester spend two hours per week 
in the lecture hall and two hours per week in the laboratory. The topics presented and their supporting laboratory activities are presented in Table 1.

The lecture and laboratory experiences are structured to fulfill several instructional objectives: (1) Provide the students with an appreciation for some interrelationships between their specific discipline and electrical engineering, 2) Provide students with rudimentary instruction in the core concepts and techniques of electrical engineering, and 3) Provide them with some skills necessary to function in a laboratory equipped with electronic instrumentation.

This traditional approach at MTU, similar to the approach at most other U.S. universities offering this course, only partially covers the needs of students majoring in other areas of engineering: (1) It covers only some limited topics in EE in detail, (2) It is not consistent with the broad range of information currently emerging in the field of EE that could be useful for other engineering fields, and 3) It does not represent and explain adequately the scientific or industrial perspectives common between non-EE engineering fields and EE.

Table 1: Current topics presented and their supporting laboratory activities in MTU.

\begin{tabular}{|c|c|}
\hline Supporting Laboratory Activity & Topic \\
\hline $\begin{array}{c}\text { Experiment 1 } \\
\text { Multimeter Measurements on DC Resistive Circuits }\end{array}$ & Circuit Elements and Laws \\
\hline & Series and Parallel Circuits \\
\hline \multirow[t]{6}{*}{$\begin{array}{c}\text { Experiment } 2 \\
\text { Simulation of DC Resistive Circuits }\end{array}$} & Node-Voltage Analysis \\
\hline & Thevenin/Norton Equivalent Circuits \\
\hline & Superposition/Wheatstone Bridge \\
\hline & Capacitance \\
\hline & Inductance \\
\hline & Transients \\
\hline \multirow[t]{3}{*}{$\begin{array}{c}\text { Experiment } 3 \\
\text { Digital Oscilloscope Familiarity }\end{array}$} & Sinusoids and Phasors \\
\hline & Complex Impedance \\
\hline & AC Power \\
\hline $\begin{array}{c}\text { Experiment } 4 \\
\text { AC Magnitude and Phase }\end{array}$ & Frequency Response \\
\hline \multirow[t]{2}{*}{$\begin{array}{c}\text { Experiment 5 } \\
\text { Frequency Response and Passive Filters }\end{array}$} & Ideal and Second-Order filters \\
\hline & Amplifiers \\
\hline $\begin{array}{l}\text { Experiment } 6 \\
\text { Op Amps }\end{array}$ & Operational Amplifiers \\
\hline $\begin{array}{c}\text { Experiment } 7 \\
\text { Introduction to Labview }\end{array}$ & Transducers \\
\hline \multirow[t]{2}{*}{$\begin{array}{c}\text { Experiment } 7 \text { (part 2) } \\
\text { Introduction to Digital Circuits }\end{array}$} & Logic Circuits \\
\hline & Computer-Based Instrumentation Systems \\
\hline
\end{tabular}




\section{Preliminary Study}

In this section, we present the preliminary study confirmed our experience in regard to the shortcomings of the traditional curriculum of the course "Introduction to Electrical Engineering for non-majors". As discussed earlier, problems associated with the traditional curriculum and technique of teaching this course can be summarized as follows: the course has deficiencies in creating the required motivation for the course; it also fails to provide proper coverage of a wide spectrum of EE concepts required for the future careers of non-EE majors.

The preliminary study was conducted with mechanical engineering majors because, statistically, ME students form the largest group of students who take this course as a part of their undergraduate degree requirements. This study can be similarly applied to the students in other engineering areas, such as civil engineering, biomedical engineering, environmental engineering and chemical engineering.

To investigate the shortcomings of the traditional curriculum, we assumed a rough model for the topics covered in the curriculum that consists of two parts: (1) Topics covered at MTU, which is almost consistent with the course taught at many other universities in the United States (see Table 2-a), and (2) Topics not covered at MTU, but containing content relevant to mechanical engineering (see Table 2-b).

To verify the consistency of this rough model, we used a survey of the faculty that teach this course and we received the results from 7 universities in the United States including California State University, University of Alabama, Colorado State University, University of Yale and University of Southern California (Writing university name was optional; and we received some of the filled questionnaires the university name). The results from this survey are reported in Figure 1. This figure represents the statistics of the universities covering the topics presented in Table 2.

To generate this figure, a grade $(1,2$, or 3$)$ was assigned to the three possible answers for each topic. The answers and their associated grades are: (1) Should not be discussed, (2) Cover only the Concept, and (3) Cover the Concept and the Details. The average grade for the answers received was generated next. The minimum possible grade for this average is 1 and the

Table 2 Topics in the Curriculum.

\begin{tabular}{|l|ll|}
\hline a. The topics covered at MTU & \multicolumn{2}{|c|}{ b. Some topics that are not covered at MTU } \\
\hline 1. Circuit Elements and Sources & Electronic Devices, & Antenna Structure \\
\hline 2. Circuit analysis concepts & Amplifiers \& Operational Amplifiers & Biomedical systems \\
\hline 3. Circuits with diverse elements & Transducers & Optical Systems \\
\hline 4. Transient and steady state Response & Logic Circuits & Wireless systems \\
\hline 5. AC analysis & Micro controllers & Satellite Communications \\
\hline 6. Other AC analysis topics & Computer based Instrumentation Systems & Microwave Systems \\
\hline 7. Measurement Equipment Operation & Basics of Communication System & Electric Machinery \\
\hline 8. Modeling Softwares & Radar System & Robotics \\
\hline
\end{tabular}



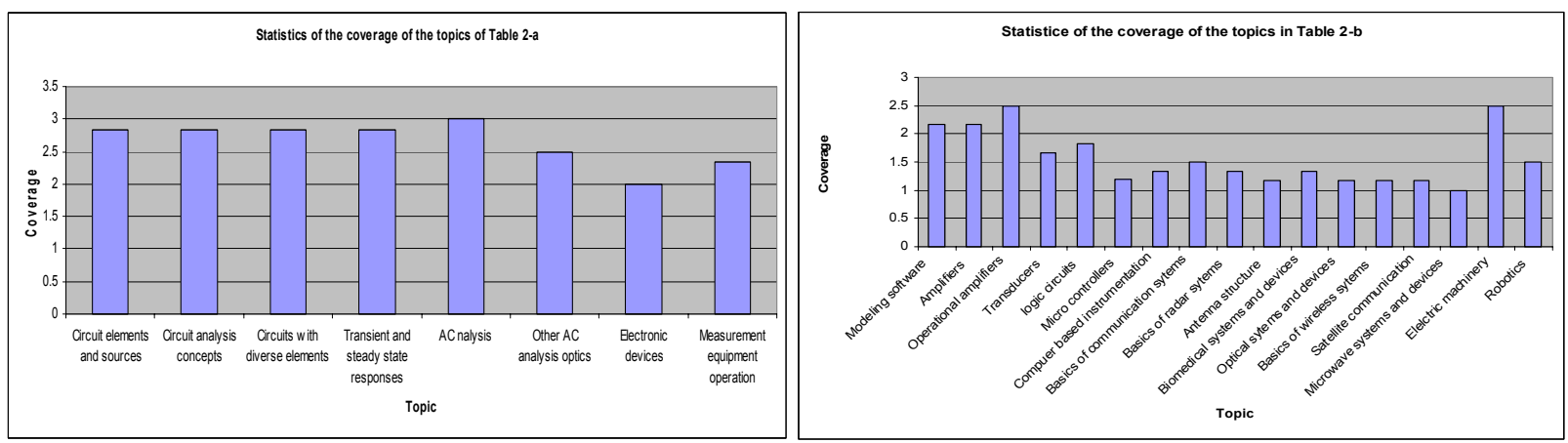

Figure 1 Statistics of the coverage of the topics introduced in Table 2(a,b) by the instructors teaching the course.

maximum is 3. Figure 1-a represents these statistics. As an example, the average 2.7, that is above 2.5, for the topic "circuit elements and sources" means that this subject is covered in about $90 \%(=2.7 / 3.0$ percent $)$ of the universities in concept and detail. In other words, this topic isstatistically covered in detail in almost all universities. Moreover, the average 2.3, which is below 2.5 for the topic "Measurement equipment operation" shows that the course is taught just in concept, statistically.

Hence, Figure 1 shows that (except for the two topics "operational amplifiers" and "electric machinery") statistically the model in Table 2-a has a good match with the topics covered at other universities, while the topics in Table 2-b is barely covered in the current approach of teaching. Hence, this figure confirms that in many universities the instructors of the EE course for non-majors cover a small spectrum of EE information.

Other surveys were developed for other groups in order to study their level of satisfaction with the current approach of teaching. These groups include: (a) the students that have passed this course and are still at the undergraduate level (Questionnaire S, in Appendix 1), (b) the students that are at the graduate level and have taken the course, and (c) faculty members in the MTU Mechanical Engineering Department. Table 3 summarizes the contents of these questionnaires. More than 90 faculty members, undergraduate students and graduate students participated in our study. The first part of the Questionnaires S, G and P refers to the degree, the major and the position of groups completing the survey.

In part II-a of Questionnaire S, and part II of Questionnaires P and G, we asked the usefulness of the concepts were taught in the course. In part II-a of Questionnaire S, we just considered the topics in Table 2-a, while in part II of questionnaires P and G, we considered all topics of Table 2(a,b). We felt undergraduate students might not have enough experience to judge the usefulness of the new subjects listed in the Table 2-b, while graduate students and faculty were considered as groups that can judge the usefulness of those topics. Hence, we split this part in to two parts just for undergraduate students (Parts II-a,b, see Table 3).

Figure 2-a shows the statistics for the topics presented in Table 2-a of all questionnaires. Figure 2-b represents the same results for the questionnaires $\mathrm{G}$ and $\mathrm{P}$ just for the topics in Table 2-b. In this figures, we have assigned a number 1-5 to the 5 possible answers to this question. That is, grade 1 to the answer "I don't remember the concept", grade 2 to "not useful", grade 3 to "Might be used", grade 4 to "Useful", and grade 5 to "Very useful". Finally, we generated an average number for the responses. 
Table 3: A summary of the contents of the questionnaires

\begin{tabular}{|c|c|c|}
\hline $\begin{array}{l}\text { Questionnaire S } \\
\text { (Undergraduates) }\end{array}$ & $\begin{array}{c}\text { Questionnaire G } \\
\text { (Graduate Students) }\end{array}$ & $\begin{array}{l}\text { Questionnaire P } \\
\text { (Professors) }\end{array}$ \\
\hline Part I: Identifying Information & Part I: Identifying Information & Part I: Identifying Information \\
\hline $\begin{array}{l}\text { Part II-a: Usefulness of Topics } \\
\text { Taught in the Class (Figure 3.a) }\end{array}$ & $\begin{array}{c}\text { Part II: Usefulness of Topics } \\
\text { Taught in Class and Potential New } \\
\text { Topics (Figure 3.a,b) }\end{array}$ & $\begin{array}{l}\text { Part II: Usefulness of Topics Taught } \\
\text { in Class and Potential New Topics } \\
\text { (Figure 3.a,b) }\end{array}$ \\
\hline $\begin{array}{c}\text { Part II-b: Exclusion/Inclusion of } \\
\text { Potential } \\
\text { Future Topics (Figure 3-c) }\end{array}$ & & \\
\hline $\begin{array}{c}\text { Part III: Which of all Topics } \\
\text { Should be Taught? Should course } \\
\text { exist? (Figure } 4 . a, b)\end{array}$ & $\begin{array}{c}\text { Part III: Which of all Topics Should } \\
\text { be Taught? } \\
\text { Should course exist? (Figure ) }\end{array}$ & $\begin{array}{c}\text { Part III: Which of all Topics } \\
\text { Should be Taught? Should course } \\
\text { exist? (Figure 6) }\end{array}$ \\
\hline
\end{tabular}

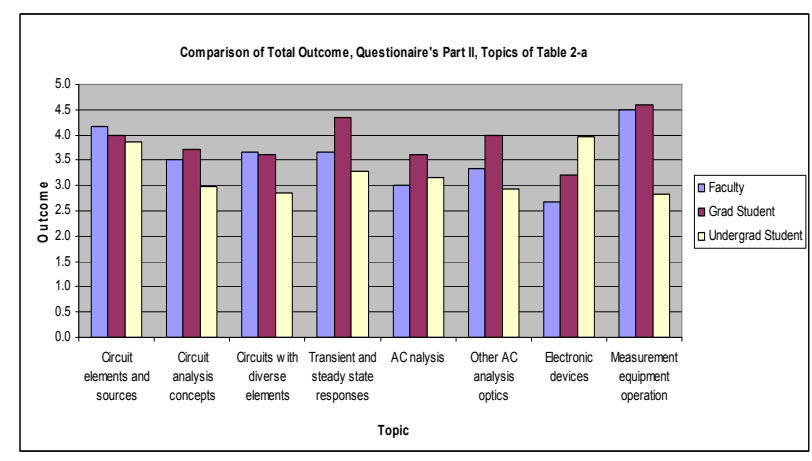

(a)

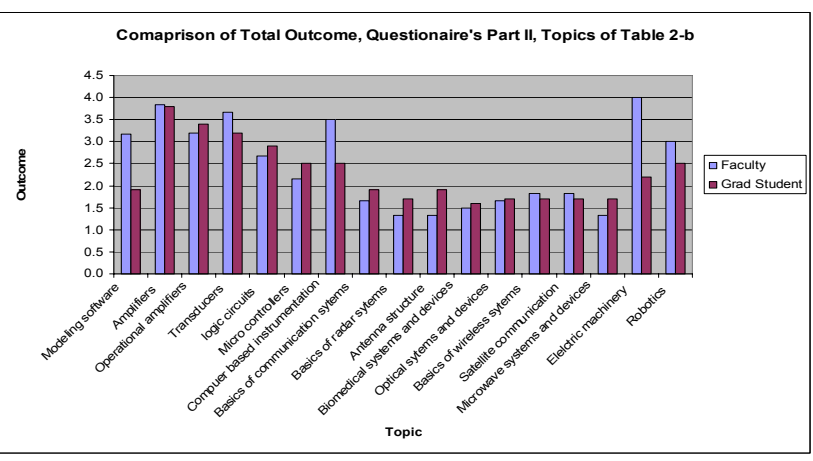

(b)

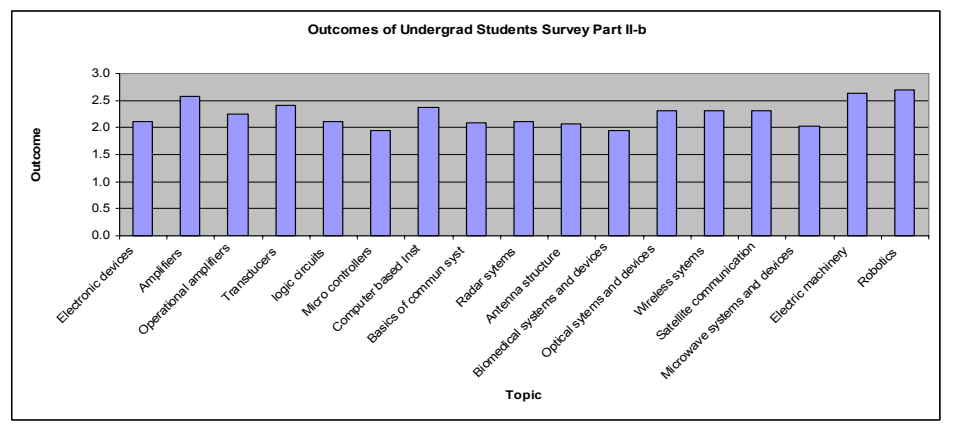

(c)

Figure 2 Outcomes of Part II, (a) Topics in Table 2-a, (b) Topics in Table 2-b for faculty and grad students, and (c) Topics in Table 2-b for undergrad students of MTU.

Here, for example in Figure 2-a, for the first topic, "Circuits Elements and Devices", the average computed is about 3.8. This means, statistically, students feel this topic has been "Useful" for them. This is also the case for the $7^{\text {th }}$ topic in Table 2-a, that is "Measurement equipments". All other topics in the Table 2-a are rated almost 3, i.e., as "might be used", in this survey.

Based on Figure 2-b, some major differences in responses of faculty members and graduate students are observed in the topics: (a) "Modeling Software", "Computer based Instrumentation Systems" and "Electric Machinery" where the faculty perceives a much higher degree of 
usefulness than grad students, and conversely in (b) "AC analysis", "Basics of Radar System" and "Antenna Structure" where grad students perceive a higher degree of usefulness than faculty.

The outcomes of part II-b of the undergraduate surveys are shown in Figure 2-c. In this part, we considered the rough model of Table 2-b for the new topics and we have asked those undergrad students "whether they think the topics provided in Table 2-b should be considered (added) in the curriculum of the course Introduction of Electrical Engineering or should they be removed". Here, we have provided three possible answers rated from 1 to 3, that is: 1. Removed, 2. Neutral and 3. Added.

Figure 2-c shows that undergrad students believe that the topics: "Amplifiers", "Electric Machinery" and "Robotics" are useful and should be considered in the curriculum while they feel "Neutral" about other topics listed in Table 2-b. None of the topics are considered to be "not-useful". Hence, we should look at the opinion of other groups and see what they feel about these topics.

Figure 3(a,b) shows the outcomes of Part III of the questionnaires S, G and P. In this part, we asked whether the topics in Table 2(a,b): 1. should not be discussed, 2. just the concept should be discussed, or 3. should be discussed in detail. Finally, we asked whether, in overall, they feel the entire course: 1 . should not be taught, 2 . should be elective, or 3 . should be required. We have assigned the grades 1,2 , and 3 to these questions respectively.

Based on the results shown in this figure, the faculty and grad students responses are $89 \%$ correlated, and undergraduate students response have almost the same correlation at $83 \%$ with both faculty and graduate students. In other words, while all of these groups have similar opinions on the subjects, undergraduate students' idea about teaching this course are slightly different from those of faculty and grad students. We intend to extend this survey to Engineers working in industry and compare their outcomes with those of the current groups.

Side-by-side comparison of the results shows that, while all groups believe this course should be required, the following main differences exist among these groups: (a) "Modeling Software": Almost all students (graduate and undergraduate) believe this topic should be discussed in detail while faculty members believe it should be discussed just in concept, (b) "Amplifiers" and "Transducers": Grad students believe this topic should be discussed in detail while the other groups believe just the concept should be discussed, (c) "Operational Amplifiers": Faculty members believe it should be discussed in detail while students groups feel that just the concept would be sufficient, and (d) "Computer based Instrumentation Systems" and "Antenna structure": Faculty members believe it should not be discussed while student groups feel the concept should be discussed. In addition, basic deductions from Figure 4 are as follows: (a) Topics 1-4 and 7 of Table 2-a should be discussed in detail, (b) Almost all other topics introduced in this study should be discussed just in concept, and (c) This course should be a required course.

In summary, on average, more than $70 \%$ of the faculty and graduate students have not included the topics listed in Table 2-b in their curriculum, but more than $60 \%$ of them believe those topics should be taught. Undergraduate students who took this course at MTU receive minimal or no instruction in those topics, but more than $80 \%$ feel that those topics should be taught. 


\section{A Novel Approach for Optimizing the Curriculum}

In general, three options are possible for delivery of the EE course to non majors (see Figure 5). The first option is the delivery via the traditional lecture and lab scheme for all non-EE students. This is what we have been doing in the traditional approach, and it is not the preferred option for reasons previously discussed.

The second option is to create the best curriculum for each non-EE student and arrange a different course for each of them (the approach selected by some universities [17], [18]). The second option provides each non-EE major student with the best approach of learning; however, we need a large number of instructors and space to cover all of these classes. Moreover, for some non-EE majors, the course content could extend beyond the time frame of one semester. This means that more than 3 credits might be required for some majors. This imposes a high cost to the universities as well as to students, and it prolongs their duration of study. For these reasons option 2 is not acceptable.

Choosing the optimum curriculum for an EE course for each non-EE major is the most challenging objective. We call the optimum curriculum for each non-EE major, the curriculum sub-space. This is a two dimensional space formed by the topics and their depth of coverage. The curriculum sub-spaces for each area are shown using a diagram in Figure 5. The horizontal axis in this diagram represents the topics should be covered for each non-EE major areas and the vertical axis shows the extent of coverage of each topic. After designing these curriculum subspaces, a new curriculum should be designed which addresses the needs of all groups of non-EE students. We call this curriculum, the curriculum final space. There are many questions that must be addressed in designing the curriculum final space:

1. A wide range of students from different engineering disciplines take this course. All of these students want to know how topics covered in this course address their interdisciplinary needs. A proper selection of those topics can address the motivational question "why do they need to take this course?" (see Kolb model [15], [16]). Hence, what topics of EE are essential for non-majors and should be covered?

2. How can the curriculum sub-space and final space be generated?

3. What percentage of each curriculum subspace should have an overlap with the curriculum final space?

4. How does the curriculum final space address the needs of different non-major students?

5. Based on our preliminary study we anticipate that a large number of topics should be included in the curriculum final space for all non EE engineering majors. What would be the best teaching technique to use in order to cover all of those topics adequately within a single semester course?

Hence, the best option (option 3 in Figure 5) is to create a curriculum final space for all of the curriculum sub-spaces (as they are generated independently for the second option). The curriculum sub-spaces are sketched in a diagram in Figure 5. The curriculum final space includes two main parts: (1) one which is common to all of the sub-spaces (shaded region in the diagram of Figure 5). This part should be covered in the class for all non-EE majors simultaneously; and (2) the part which is not common to the subspaces. This part should be covered using different 
Web-based systems created for different non-EE majors (areas) and their associated Laboratory experiments.

Web based education is a delivery strategy that maximizes the efficiency and effectiveness of time spent in the classroom to deliver basic instruction, practice materials, and formative assessment. The use of this tool to augment the traditional lecture format rather than replace it will allow presentations in the classroom or lecture hall to focus on the interdisciplinary nature of engineering practice. Concentration on the effective learning domain [19] in the classroom has the potential to enable faculty to frame basic electrical engineering principles in the context of other engineering disciplines through the use of examples from research and industry. Furthermore, by firmly making the connection between disciplines, students may be more strongly motivated to pursue basic skills and knowledge through the web based strategy. By translating the specific topics defined by the optimized curriculum space into reusable online learning objects [20] it will be possible to tailor individual learning experiences for each non-EE major with minimum effort and expense.

\section{Option 1}
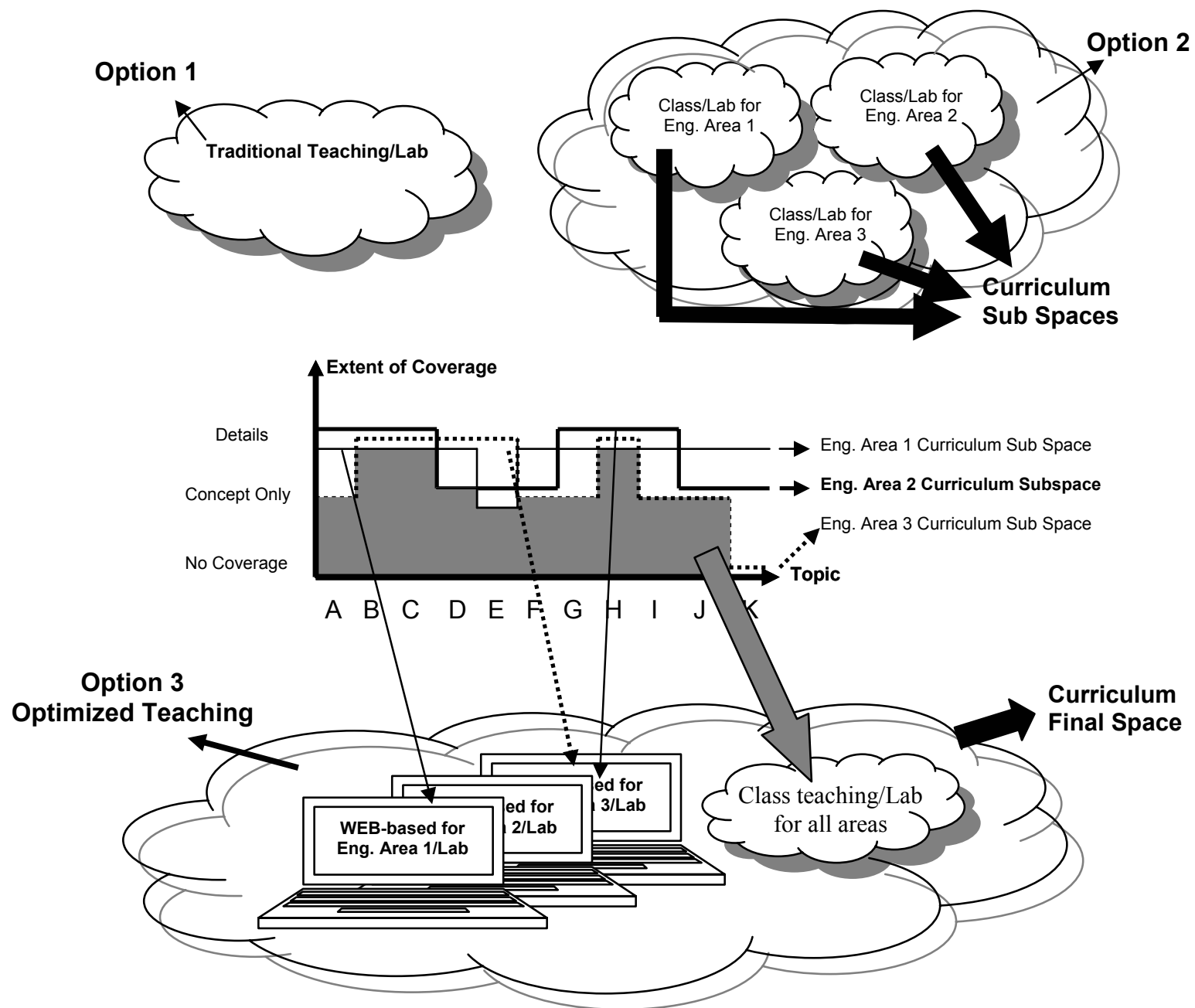

Figure 5 Options of teaching, Curriculum Sub-Spaces and Curriculum Final Space. 
An example is WebCT, which is an off the shelf third generation web based instruction system developed by the University of British Columbia, is in use at Michigan Tech and can be the platform of choice for this approach. Web based learning strategies provide students access to learning experiences at all times, an increasingly attractive characteristic. In addition, this technology presents the ability for learning-disabled students to work at whatever pace and under what ever circumstances best facilitates their learning. Hence, WEB-based systems help by:

a. Enhancing the efficient delivery of knowledge,

b. Avoiding addition of courses and credits for delivery of required knowledge to each nonEE students, and

c. Maximizing the efficiency of the time spent in the classroom.

\section{Conclusions}

In this paper, a study on the performance of the interdisciplinary course: "Introduction to the Electrical Engineering" for non-EE majors introduced. The results of this study indicate that more than $75 \%$ of those surveyed believe that there are problems associated with the traditional curriculum and teaching strategies for this service course. Some of the conclusions that may be drawn are: (a) The content of this course is often a cut-and-paste combination of courses offered to the electrical engineering major students. The traditional approach is not fully consistent with emerging interdisciplinary technology and does fulfill students' future needs properly; (b) It often covers a limited number of topics important to electrical engineering in great detail, but fails to cover a broad range of emerging technologies that are relevant to the non-EE engineering students; and (c) This course fails to make the connection between the students' chosen field and the instruction at hand, and it fails to create the required motivation to satisfy the current tasks. Nor does this course encourage the life long learning necessary to keep pace with the evolving engineering industry.

We proposed an innovative approach for optimizing this interdisciplinary course: An independent curriculum sub-spaces for each non-EE major should be created, and those sub-spaces should be used to construct the curriculum final space. Curriculum final space should consist of a) class teaching, b) a set of Web-based systems, each for one non-EE major, and c) Laboratory. Lab experiments associated with the parts covered in the class would be the same for all non-EE majors. Lab experiments associated with the parts covered by the Web-based system can be different for various non-EE majors. The study on this novel approach has just been started at Michigan Tech. 


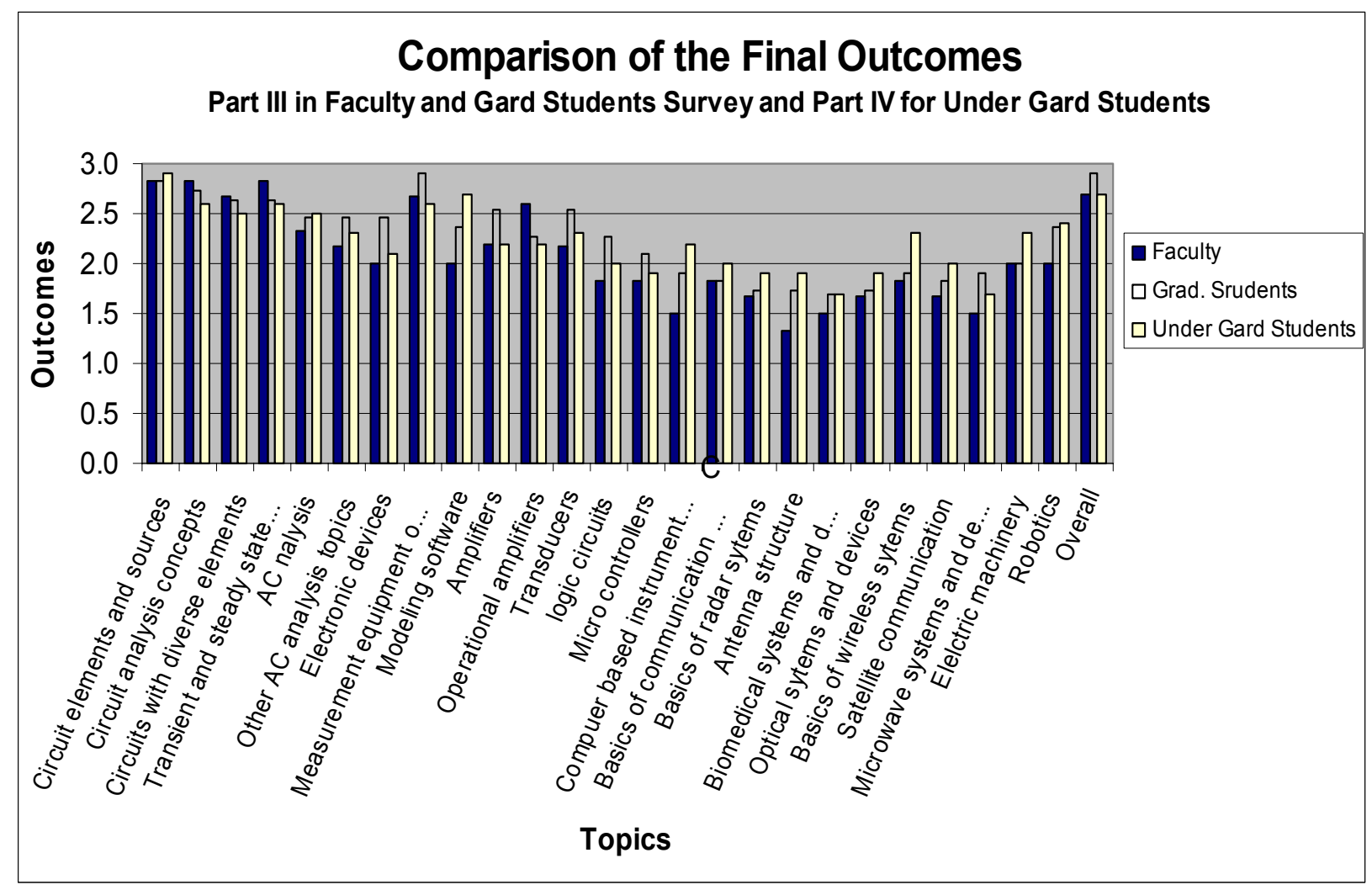

(a)

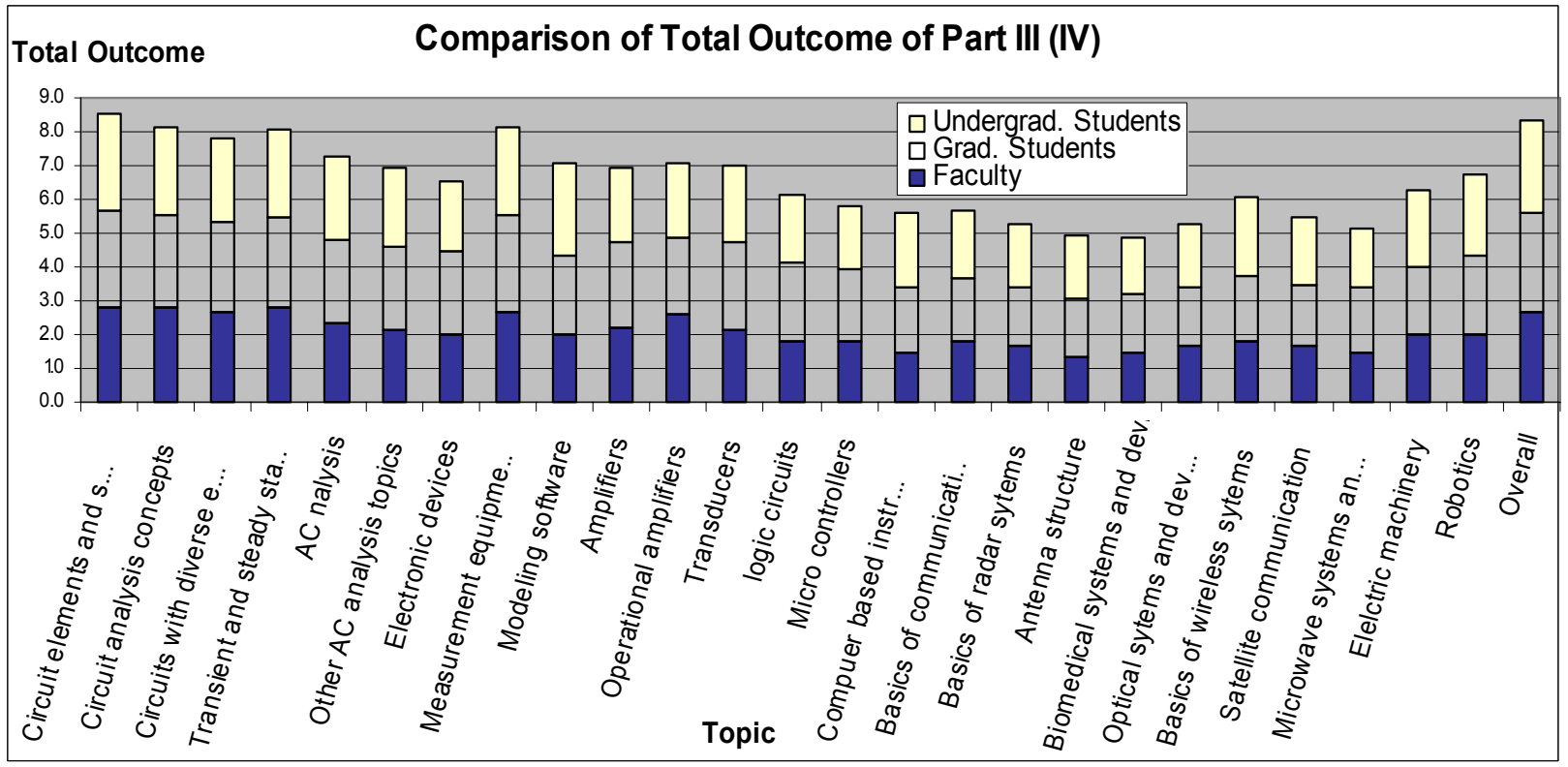

(b)

Figure 3 The Outcomes of Part III of Faculties and Grad. Students and Part IV of Undergrad. Students: a) side by side comparison, and b) total outcome. 


\section{References}

[1] F. Bronet, R. Eglash, G. Gabriele, D. Hess and Larry Kagan, "Product design and Innovation: Evaluation of an Interdisciplinary design curriculum," International Journal on Engineering Education, Vol. 19, No. 1, pp. 183-191, 2003.

[2] U. Roy, "Preparing Engineers for future with collaborative technology," Journal of Computer Applications in Engineering Education, No. 2, pp. 99-104, 1998.

[3] J. Bordogna, E. Fromm and E. W. Ernst, "Engineering Education: Innovation through integration," Journal of Engineering Education, Vol. 82, No. 1, pp. 3-8, 1993.

[4] A. M. Massom and D. J. Wilson, "Development of a freshman orientation course in engineering," proceedings 1995 ASEE annual conference, pp. 871-875, Anaheim, CA, June 25-28, 1995.

[5] R. M. Felder and R Brent, "Designing and teaching courses to satisfy the ABET engineering criteria," Journal of Engineering Education, Vol. 92, No. 1, pp. 7-18, Jan. 2003.

[6] B. K. Hodge, R. P. Taylor, "development and evolution of an energy systems design course," Proceedings the $3^{\text {rd }}$ Conference on Engineering Education, Vol. 2, Portsmouth, England, pp. 241-245, Sept. 1992.

[7] Proceedings of the National Congress on Engineering Education, Accreditation Board for Engineering and Technology, 1987.

[8] S. Sarin, A plan for addressing ABET criteria 2002 requirements, Proceedings 1998 Annual Meeting, American Society for Engineering Education.

[9] F. T. Najafi and I. Tag, "New trends and context for change in engineering education," Proceedings 1995 ASEE annual conference, pp. 944-949, Anaheim, CA, June 25-28, 1995.

[10]Engineering Education and Practice in the United States-Foundations of Our TechnoEconomic Future, National Research Council, 1985.

[11] Quality of Engineering Education, American Association for Engineering Education, 1986

[12] National Agenda for Engineering Education, American Association for Engineering Education, 1987.

[13] R. F. Mager, Preparing Instructional Objectives, Pitman, CA, 1975.

[14] D. M. Pai and R. A. Deblasio, "Enhanced learning from an industry-university partnership," Journal of Industry and higher education, pp. 224-228, Aug. 1997.

[15] D. A. Kolb, Experiential learning: Experiences as the source of learning and development, Prentice-Hall, Englewood Cliffs, NJ, 1984.

[16] J. N. Harb, S. O. Durrant, and R. E. Terry, "Use of the Kolb learning cycle and the 4MAT system in engineering education," Journal of Engineering Education, Vol. 82, No. 2, Apr. 1993.

[17] B. K. Hodge and W. G. Steele, "Experiences with a curriculum with balanced design content in all stems," Proceedings 1995 ASEE annual conference, pp. 1305-1310, Anaheim, CA, June 25-28, 1995.

[18] D. K. Anand, P.F. Cunniff, J. W. Dally, J.H. Duncan, E. B. Magrab, R. K. Radermacher, J. S. Sirkis and W. H. Walston, "A mechanical engineering curriculum for the next decade," Proceedings 1995 ASEE annual conference, pp. 2138-2144, Anaheim, CA, June 25-28, 1995.

[19] http://www.vanth.org

[20] D. Krathwohl, B. Bloom, and Masia, B., Taxonomy of educational objectives. Handbook II: Affective domain, New York: David McKay 


\section{Biography}

Seyed Alireza Zekavat received his Ph.D. degree in Electrical and Computer Engineering from Colorado State University, Fort Collins, CO, USA in 2002. Since August 2002 he has been with Dept. of Electrical and Computer Engineering, Michigan Tech University (MTU), Houghton, MI, USA. His research interests include Wireless Communications, Radar Theory, Statistical Modeling, Adaptive Beam Forming and Neural Networks. He is the director of the laboratory for wireless communication research in MTU. He has published over 35 journal and conference papers and has co-authored the book Multi-Carrier Technologies for Wireless Communications.

Corina Sandu is currently an assistant professor in the Mechanical Engineering Department at Virginia Polytechnic Institute and State University, and the associate director of the Advanced Vehicle Dynamics Laboratory. She published more than thirteen journal, proceedings and conference papers. Her current research concerns the modeling and simulation of mechanical systems, tracked vehicles, vehicle dynamics, multibody dynamics, advanced engineering environments, and engineering education. Dr. Sandu obtained her M.S. and Ph.D. in ME from the University of Iowa; prior to joining Virginia Tech she taught for three years at Michigan Tech.

Glen Archer is a member of faculty at MTU. He received his Master degree from Texas Tech University in 1986. He has been the instructor of EE service course and its associated laboratories since Fall 2001, and has 10 total years of teaching experience. He supervises and develops all undergraduate core laboratories in the Department of Electrical and Computer Engineering.

Kedmon Hungwe is with Department of Education, Michigan Technological University. His research interests focus on teaching and learning in school, college and out-of-school contexts. He has a particular interest in the transfer of knowledge between and within contexts. 


\section{Appendix 1}

\section{Curriculum Improvement Questionnaire S}

The purpose for this survey is to improve the course Electrical Engineering for non-EE majors. Many instructors of this course believe that the current syllabus of this course is not appealing for non-EE majors, such as Mechanical Engineering students. In general, we believe that this course would be extremely useful and interesting if non-EE students learn as much as possible the concepts common to electrical engineering and their own area of study. We are therefore investigating an alternative syllabus for the course. We are inviting you to make comments about what should be included, and the depth to which it should be covered. Please take some time to respond the following questions. Thank you.

\section{Part I}

Please provide us with the following information: (Circle one)

1. Please specify in what year of your degree you are:
a. Senior
b. Junior
c. Sophomore

2. What is your major?
a. Mechanical Engineer
b. Civil Engineer
c. Chemistry Engineer
d. Others (Please Specify)

3. Have you taken the course Introduction to Electrical Engineering:
a. Within last year
b. Between 1-2 years ago
c. More than 2 years ago

4. If you are a Mechanical Engineer, please specify the area of concentration.
a. Solid Mechanics
b. Energy and thermo fluids
c. Design dynamic systems
d. Others (please specify)

\section{Part II}

The following concepts were taught in the course Introduction of Electrical Engineering. Please specify how useful they have been in the course of your career. Check the box that best reflects your point of view.
I Don't Remember Not Useful Might be Useful Very Useful if the concept Used

1. Circuit Elements and Sources (Including: Resistor, Capacitor, Inductor, Serial and Parallel Resistors, Electric Source (Current Source, Voltage Source)),

2. Circuit analysis concepts (Including: node and mesh analysis, Thevenin and Norton Equivalent Circuits, Super Position (if more than one source is available), Wheatstone Bridge.)

3. Circuits with diverse elements (Including: Resistive-Inductive (RL), Resistive-Capacitive (RC), and RLC circuits)

4. Transient and steady state Response

5. AC Analysis (Including: Phasors analysis, Complex impedance, $A C$ and $D C$ power)

6. Other $\mathrm{AC}$ analysis topics. 
(Including: Impedance Matching (Maximum Power Transfer), Frequency Response, Filters (ideal and $2^{\text {nd }}$ order)) ))

7. Measurement Equipment Operation

(Including: Oscilloscope, Multi-meter, Function Generator, Power Supply)

8. Modeling Softwares

(Including: Labview, P-Spice, ...)

\section{Part III}

Please specify whether you think the following topics should be considered in the curriculum of the course Introduction of Electrical Engineering or they should be removed.

\section{Not Useful/Removed Neutral Useful/added}

1. Electronic Devices, (Including: Solid State Materials, P-N junction Diode, Transistors (PNP and NPN), other Transistors and diodes)

2. Amplifiers (Including: Amplifiers DC Analysis (operational point), Amplifiers AC Analysis (Voltage Gain and Current Gain))

3. Operational Amplifiers

4. Transducers

5. Logic Circuits

6. Micro controllers

7. Computer based Instrumentation Systems

8. Basics of Communication System

9. Radar System

10. Antenna Structure

11. Biomedical systems and devices

12. Optical Systems and Devices

13. Wireless systems

14. Satellite Communications

15. Microwave Systems and Devices

16. Electric Machinery

17. Robotics

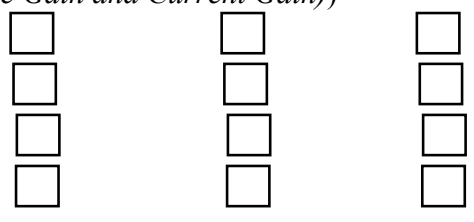

\section{Part IV}

Please specify how deep the theory of the following concepts should be presented in the course Introduction of Electrical Engineering.

Shouldn't be discussed

Just the Concept

Concept \& details

1. Circuit Elements and Sources (Including: Resistor, Capacitor, Inductor, Serial and Parallel Resistors, Electric Source (Current Source, Voltage Source))

2. Circuit analysis concepts (Including: node and mesh analysis, Thevenin and Norton Equivalent Circuits, Super Position (if more than one source is available),

Wheatstone Bridge.)

3. Circuits with a Combination of elements (Including: Resistive-Inductive (RL), Resistive-Capacitive ( $R C)$, and RLC circuits)

4. Transient and Steady State Responses

5. AC Analysis

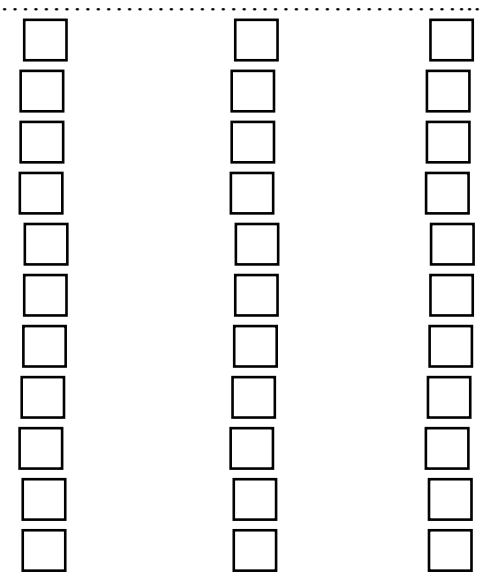


(Including: Phasors analysis, Complex impedance, $A C$ and DC power)

6. Other AC analysis topics.

(Including: Impedance Matching (Maximum Power Transfer), Frequency Response, Filters (ideal and $2^{\text {nd }}$ order))

7. Electronic Devices,

(Including: Solid State Materials, P-N junction Diode, Transistors (PNP and NPN), other Transistors and diodes)

8. Amplifiers

(Including: Amplifiers DC Analysis (operational point), Amplifiers AC Analysis (Voltage Gain and Current Gain))

9. Measurement Equipment Operation

(Including: Oscilloscope, Multi-meter, Function Generator, Power Supply)

10. Modeling Softwares

(Including: Labview, P-Spice, ...)

11. Operational Amplifiers

12. Transducers

13. Logic Circuits

14. Micro controllers

15. Computer based Instrumentation Systems

16. Basics of Communication System

17. Basics of Radar Systems

18. Antenna Structure

19. Biomedical systems and devices

20. Optical Systems and Devices

21. Basics of Wireless systems

22. Satellite Communications

23. Microwave Systems and Devices

24. Electric Machinery

25. Robotics

Your General impression of this course:

Should not be taught

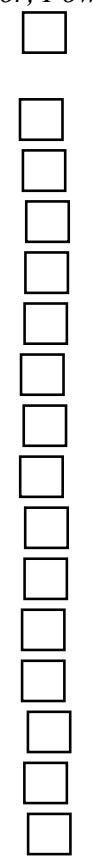

Should be Elective $\square$

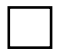

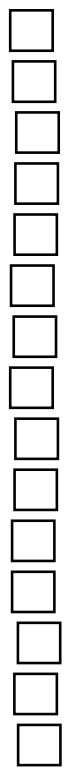

0
0
0
0
0
0
0
0
$\vec{v}$ 